\title{
Technique for the Retrospective and Predictive Analysis of Cognitive Errors in Maritime Pilotage Operation
}

\author{
Mohd Hafizi Said* and Muhamad Faiz Amir Mohd Noor \\ Program of Nautical Science and Maritime Transportation, School of Ocean Engineering, \\ Universiti Malaysia Terengganu, Kuala Nerus, Terengganu, Malaysia \\ hafizi@umt.edu.my \\ *corresponding author
}

Keywords: Accident Investigation Report, Human Error Identification, Maritime Pilotage Operations, TRACEr.

Abstract: This paper presents one of the human error identification method called Technique for the Retrospective and Predictive Analysis of Cognitive Errors (TRACEr). This method has been actively used in the human reliability studies of air traffic management and the rail operations. Interestingly, there are only a few published literatures where this method has been applied to maritime operation. Therefore, this paper was attempted of applying the TRACEr methodology in order to analyze and classify the maritime pilots' cognitive errors. For that reason, 50 accident investigation reports in the maritime pilotage operations were reviewed to demonstrate TRACEr capability. Finally, concluding remarks and further extensions in practicing TRACEr are discussed at the end of this paper.

\section{Introduction}

Technique for the Retrospective and Predictive Analysis of Cognitive Errors (TRACEr) is a comprehensive approach for human error identification and it was initially developed for the UK National Air Traffic Services following the need to analyze the aircraft proximity (Airprox) accidents reports [1]. Accordingly, this method has been applied in a number of European Organization projects for the safety study of air navigation (EUROCONTROL), particularly the study of air traffic controller errors [2,3]. TRACEr was also adapted and applied in the rail industry by the UK Rail Safety and Standards Board (RSSB). In the beginning of applying TRACEr (Rail), it has been used to analyze the accidents cause by the train driver errors [4]. Subsequently, TRACER has appeared to be the most frequently used of HEI tool for the other rail safety studies in the UK and Australia $[4,5,6$,

Furthermore, this tool has been used in the medical industry in order to develop medical human factor taxonomies [7]. Recently, TRACERr has been adapted for maritime operation accident investigation [8] and [9]. Therefore, it is believed that, TRACEr should also suitable for pilotage operations because of some similarities with the aforementioned studies in the context of the type of tasks, performance shaping factors and human cognitive aspect. 


\section{Literature Review}

The theoretical framework of TRACEr was developed on two established scientific theories, based on Wickens model [10] and Simple Model of Cognition (SMoC) of Rasmussen [11]. Neville has described in specific the relationship between these theories [12]. Theoretically, TRACEr was developed in an interactive fashion with input from a variety of activities, including an experimental study, analysis of real accident reports, interview and discussion with experts [1]. As shown in Table 1, TRACEr comprises eight taxonomy groups which were derived from the cognitive error theories that described earlier [1, 4, 6]. In general, TRACEr is divided into two approaches namely retrospective and predictive. Both of these approaches use a set of a specific taxonomy and related guidewords to identify human errors. However, due to the main objective of the study in this paper which is to identify and classify the pilot errors from the accident investigation reports, therefore the first approach (retrospective) is more suitable to apply.

Table 1: The Description of Tracer Taxonomies [4].

\begin{tabular}{|c|c|}
\hline Taxonomy/category & Description \\
\hline 1. Task errors & $\begin{array}{l}\text { Describe human error in term of task that was not } \\
\text { performed satisfactorily. }\end{array}$ \\
\hline 2. Cognitive domain & $\begin{array}{l}\text { Describe the process within which the error occurs } \\
\text { (perception, memory, decision, action and violation). }\end{array}$ \\
\hline 3. Internal error modes (IEM) & $\begin{array}{l}\text { Describe what cognitive function failed or could fail and } \\
\text { in what way. }\end{array}$ \\
\hline $\begin{array}{l}\text { 4. Psychological error mechanism } \\
\text { (PEM) }\end{array}$ & $\begin{array}{l}\text { Describe the psychological nature of the IEMs, the } \\
\text { cognitive biases that are known to affect performance. }\end{array}$ \\
\hline 5. Error information & Describe the subject matter or the topic of the error. \\
\hline 6. Error recovery & $\begin{array}{l}\text { Classifies how the driver was recovered and what factors } \\
\text { influenced the recovery of the error. }\end{array}$ \\
\hline $\begin{array}{l}\text { 7. Performance Shaping Factor } \\
\text { (PSF) }\end{array}$ & $\begin{array}{l}\text { Classifies factors that have influenced or could influence } \\
\text { performance, aggravating the occurrence of errors or } \\
\text { assisting error recovery. }\end{array}$ \\
\hline 8. Causality level & $\begin{array}{l}\text { Human error is classified as being causal, contributory, } \\
\text { compounding or non-contributory. }\end{array}$ \\
\hline
\end{tabular}

The process of developing individual taxonomies within this new method has been conducted by the main researcher. In order to ensure the new taxonomies are valid and relevant to be applied in the pilotage operations, two experts were appointed for the reviewing process. Both experts have more than 15 years of experienced in investigation of maritime accidents and also have the background in navigation and pilotage operations. They were required to review a full set of taxonomy and classification. This set consists of taxonomies groups similar to the Table 1, but with more specific on the pilotage operations aspect. As a result, after considering the experts views, some modifications have been made including changed the task error taxonomy and the PSFs. Table 2 summaries the modifications that have been made on the previous versions of TRACEr for its application in maritime pilotage operations. 
Table 2: The Proposed Tracer in Maritime Domain Application

\begin{tabular}{|l|l|}
\hline \multicolumn{1}{|c|}{ Taxonomy/category } & \multicolumn{1}{|c|}{ Propose TRACEr for Maritime Pilotage Operation } \\
\hline Task error & $\begin{array}{l}\text { Nine specific categories and sub categories of maritime pilot } \\
\text { tasks were selected based on the formal manual of National } \\
\text { Occupational Standard (NOS), UK. }\end{array}$ \\
\hline Cognitive error domain & $\begin{array}{l}\text { Based on the expert's suggestion, the violation category was } \\
\text { removed thus only four main cognitive domains namely } \\
\text { perception, decision making, action and memory were included } \\
\text { inthis modified method. }\end{array}$ \\
\hline Information or subject of error & $\begin{array}{l}\text { Many information keywords were added if they appeared to be } \\
\text { missing, and removed if not relevant with maritime pilotage } \\
\text { operation. }\end{array}$ \\
\hline actions & $\begin{array}{l}\text { This category has been removed from this study due to many } \\
\text { overlapping in terms and created confusions to many } \\
\text { respondents. It was suggested that this category is more relevant } \\
\text { to TRACER (predictive) approach. }\end{array}$ \\
\hline Performance shaping factor & $\begin{array}{l}\text { Main and sub factors were added if they appeared to be missing, } \\
\text { and removed if not relevant with maritime pilotage operation. } \\
\text { Some specific factors to pilotage operation were added such as } \\
\text { Social and Bridge Team Management (BTM), } \\
\text { Machinery/propulsion and human machine interaction and } \\
\text { Aspect of Communication and Information. }\end{array}$ \\
\hline
\end{tabular}

The flow diagram in Figure 1 represents the systematic process of the new TRACEr (retrospective) methodology and it is consists of 6 main steps. Each of the selected accident report will be analyzed one by one via these steps. The classification processes along with this analysis were made used of the specific maritime pilotage taxonomy groups which have been modified and validated earlier.

\section{The Case Study: An Analysis of 50 MPO Accident Investigation Reports}

\subsection{Background of the Case Studies}

A total of 365 accident investigation reports were reviewed. All of these reports were related to maritime pilotage accidents which are available to public access in several databases provided by the accident investigation bodies and ship classification societies. However, after a number of exclusion stages, only 153 accident reports are meeting the criteria of analysis. However, for the purpose of demonstrating the application of the new TRACEr (retrospective) methodology, only 50 out of 153 accident investigation reports were analyzed as shown in Table 3. These reports were selected as all of it contained a full description on pilot cognitive errors or the descriptions on the involvement of pilot error in such accidents. The criteria for selecting the reports were as followed:

a) Covered the period of accidents between 2007 and 2016.

b) Accident is occurred during pilotage operation when the pilot is onboard such a case with any pilotage operation conducted by the ship's master who has held the PEC is not considered. 
c) Select the pilot error accidents involved with the merchant vessels more than 500 GRT thus all naval and government agency vessels are not considered.

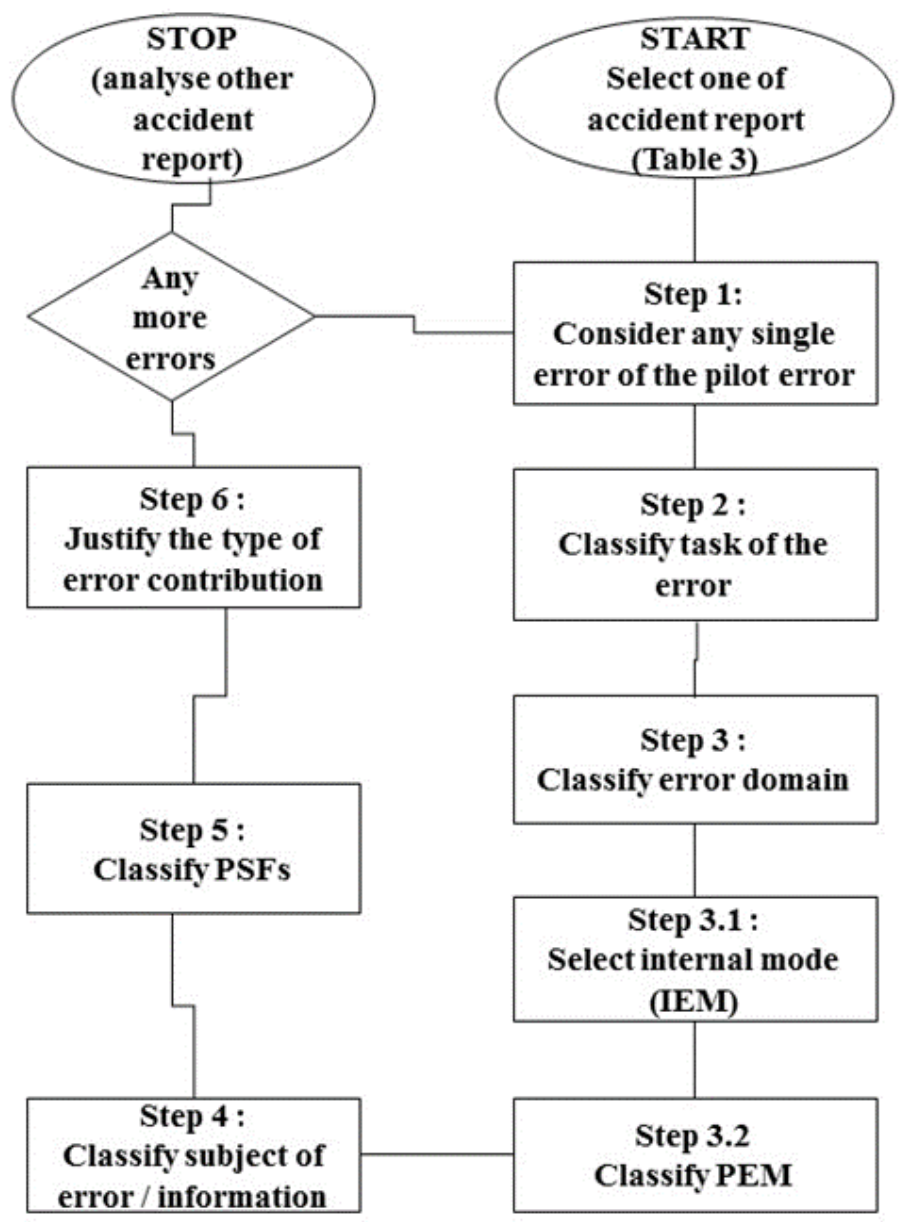

Figure 1: Framework of TRACEr for Cognitive Errors Identification in Maritime Pilotage Operation (Adapted From [1]) 


\subsection{Analysis process, results and discussion}

Table 3: The List of 50 Accident Investigation Reports and Its Respective Sources

\begin{tabular}{|c|c|}
\hline Name of case accident (occurred or reported) & Year of accident (occurred or reported) \\
\hline 1. Hunan & 2016 \\
\hline 2. Sparna, & 2016 \\
\hline 3. New Katerina & 2016 \\
\hline 4. Saluzi, & 2015 \\
\hline 5. Grande Colonia & 2015 \\
\hline 6. Amber & 2015 \\
\hline 7. Oocl Europe & 2015 \\
\hline 8. Ct Dublin & 2015 \\
\hline 9. Vectis Eagle & 2014 \\
\hline 10.Msc Jilhan & 2014 \\
\hline 11. Marigold & 2014 \\
\hline 12. Kota Wajar \& Blazing Keel & 2014 \\
\hline 13. Cape Eagle & 2014 \\
\hline 14.Star Of Luck & 2014 \\
\hline 15.Emma Maersk & 2013 \\
\hline 16. Msc Magnifica & 2013 \\
\hline 17. Green Field $1 \&$ Eureka 1 & 2013 \\
\hline 18. Wilson Leith & 2013 \\
\hline 19. Malacca Highway \& Myan Aung & 2013 \\
\hline 20. Alexander Tvardovskiy, UKD Bluefin \& Wilson Hawk & 2012 \\
\hline 21. Cape Apricot & 2012 \\
\hline 22. Tundra & 2012 \\
\hline 23. Yuan Tong & 2012 \\
\hline 24.Purki & 2011 \\
\hline 25. Bbc Steinhoeft & 2011 \\
\hline 26. Erk \& Stellar Grace & 2011 \\
\hline 27. Christopher \& Clipper Miki & 2010 \\
\hline 28. Malaga \& WMS Harlinge & 2010 \\
\hline 29. Grand Rodosi \& Apollo S & 2010 \\
\hline 30. Norman Arrow & 2010 \\
\hline 31.Ems Trader & 2009 \\
\hline 32. Spring Panda \& TMV Liquid Gold & 2009 \\
\hline 33. Golden Venus & 2009 \\
\hline 34. Hoegh London & 2009 \\
\hline 35. Birka Express & 2009 \\
\hline 36. Maersk Duffield & 2009 \\
\hline 37. Sh Grace & 2009 \\
\hline 38. Yohjin & 2009 \\
\hline 39. Nordic Diana \& RMS Saimaa & 2008 \\
\hline 40. Crete Cement & 2008 \\
\hline 41. Msc Serena & 2008 \\
\hline 42. Van Gogh & 2008 \\
\hline 43. Fu Hua & 2008 \\
\hline 44. Devprayag & 2008 \\
\hline 45. Adrekni \& M/T Lance Naik Karam Singh & 2007 \\
\hline 46. Ji Mei Long & 2007 \\
\hline 47.Leonis \& M.T. Audacity & 2007 \\
\hline 48. Prinkipo \& Mv WMS Harlinge & 2007 \\
\hline 49. Antilles Ii & 2007 \\
\hline 50. Sea Express I \& Alaska Rainbow & 2007 \\
\hline
\end{tabular}


The whole process of demonstrating the application of TRACEr (retrospective) methodology was based on the diagram flows in Figure 1. As a result, the analysis and its findings have been summarized as follow:

\subsubsection{Step 1: Identifying of errors from the selected accident investigation report}

Each of the 50 accident reports were reviewed one by one and all the pilot errors identified from each of these reports were recorded on the recording form. Overall, 106 pilot errors were identified and this represents an at least one pilot errors were occurred in each pilotage accident report

\subsubsection{Step 2: Classify the task of each pillot error}

Each of the errors identified in Step 1 then requires to be classified into the best task taxonomy which can be selected from the list of pilot task error. This list consists of nine tasks and only one of the best tasks that the error falls under should be selected. For instance, if the report mentioned that "the pilot failed to assess the effectiveness of the bridge team members" therefore, this error will be considered under the task of co-operating with the bridge members and functioning within it.

The findings of the task error analysis are shown in Tables 4 . It can be seen that 18 errors are classified as error in the task of co-operating with the bridge team and functioning within it. The result may be explained by the fact that this task is strongly related to the concept of the bridge team management which required the pilot to integrate fully within the bridge team. Further analysis on this task has showed that many pilots were failed to establish a close working relationship with all bridge members. Some good examples of this failure are described in the accident reports such as Van Gogh and New Caterina.

It also shown that, a number of pilots were failed to exchange and seek important information with the ship's master. This types information are including an intended port passage planning, critical stages/ points of the passage, contingencies manoeuvre and defective of navigation aids. To conclude the findings in this step, the comprehensive and systematic way of identify and recording the human task error could be performed by using TRACEr. These task errors could be used for further work such as the development of the risk analysis model such as in the hierarchical task analysis (HTA) model.

Table 4: Pilot Errors Identified in 50 Accident Reports

\begin{tabular}{|c|c|}
\hline Pilot Error group/taxonomy & Number \\
\hline 1. Planning an act of pilotage & 12 \\
\hline 2. Embarking and disembarking & 12 \\
\hline 3. Assessing standards on the piloted vessel & 12 \\
\hline 4. Co-operating with the bridge team and functioning within it & 18 \\
\hline 5. Transiting the pilotage area & 10 \\
\hline 6. Liaising and Communication with shore or other external parties. & 12 \\
\hline 7. Manoeuvring vessel in harbour and their approaches & 13 \\
\hline 8. Reacting and responding to problems and emergency situation. & 10 \\
\hline 9. Managing personal and professional conduct and development. & 7 \\
\hline Total & 106 \\
\hline
\end{tabular}




\subsubsection{Step 3: Selection of Error Domain, Internal Error Modes (IEMs) and Psychological error Mechanisms (PEMs)}

This step is representing the unique of TRACEr methodology. Only a few HEI methods could analyse the human cognitive domains as comprehensively as in this steps. Therefore, this step consists of three processes. Firstly, it is required to choose the cognitive domains that potentially apply to the error under consideration. Secondly, the most likely IEM is required for the identified domain is chosen. The single most appropriate IEM should be selected from the identified domains and recorded. Thirdly, the most possible PEMs are chosen that correspond to the same domain identified in the second process. For instance, if the IEsM is selected in the Memory domain, then the PEMs are also to be selected in the Memory domain. Conversely, more than one PEM can be selected for each error. IEMs and PEMs relates to the functions of the cognitive domain. IEMs describe the internal taxonomy of the pilot's error within each cognitive domain. While, PEMs describe how the error occurred in terms of its psychological mechanism within each cognitive domain.

Table 5: Number of Pilot Cognitive Error Identified in 50 Accident Report According to Its Respective Error Domain

\begin{tabular}{|l|c|}
\hline Cognitive error domain & Number \\
\hline Action & 14 \\
\hline Decision making & 21 \\
\hline Memory & 9 \\
\hline Perception & 8 \\
\hline
\end{tabular}

Table 5 shows all the 106 pilot errors that have been classified into their respective cognitive domains. However, this table only shows the result of the first process in this step which to determine the cognitive domains. From the result, it seems that the most common domain of the pilot cognitive error was that of decision making. Table 6 provides an example of the results from the second and third process in this step, with regard to internal and psychological errors respectively. This valuable information is almost impossible to obtain without applying any comprehensive HEI method such as TRACEr. This kind of information is very useful especially in the process of building the cognitive error model for a detail human error study. Thus, it can be suggested that the TRACEr method managed to highlight and explained the errors concerning human cognitive aspects.

Table 6: An Example of IEM and PEM From The Domain of Decision Making

\begin{tabular}{|c|c|c|c|}
\hline $\begin{array}{l}\text { Internal Error Mode } \\
\text { (IEM) }\end{array}$ & Numbers & $\begin{array}{l}\text { Psychology Error Mechanism } \\
\text { (PEM) }\end{array}$ & Numbers \\
\hline Mis-projection & 3 & Mis-interpretation & 3 \\
\hline $\begin{array}{l}\text { Poor decision and poor } \\
\text { planning }\end{array}$ & 17 & $\begin{array}{l}\text { Failure to consider side or long } \\
\text { term effects }\end{array}$ & 10 \\
\hline Late decision or late & 2 & Mind set & 2 \\
\hline planning & & Knowledge / Competency problem & 5 \\
\hline No decision or no & 8 & Decision freeze or overloaded & 6 \\
\hline planning & & Risk recognition failure & 12 \\
\hline
\end{tabular}




\subsubsection{Step 4: Information of error / subject of error}

The information taxonomy describes the subject of error, and the terms within the taxonomy which are related to the IEM. The information taxonomy contains over 25 keywords. An example of the information taxonomy is shown in Table 7.

Table 7: Number of Information Taxonomies That Related to 106 Pilot Errors

\begin{tabular}{|l|c|}
\hline Group & Number \\
\hline Pilot activities & 44 \\
\hline Ship particular (fixed information) & 5 \\
\hline Ship particular (variable information) & 10 \\
\hline
\end{tabular}

\subsubsection{Step 5: Performance Shaping Factors (PSF)。}

In this step, the PSFs taxonomies are selected from the list of the 9 PSFs Group. Fundamentally, the PSF will identify an individual factor of the contextual human error associated with each particular error. In other words, PSF might help to explain why the pilot made the errors. Table 8 shows the groups and quantity of PSFs associated with the 106 pilot errors. In TRACER, all PSF taxonomies are in negative form in order to indicate the negative impact on the contextual human factors issues [3]. The results of this analysis indicated that the aspect of communication and information sharing was the largest impact on the performance of pilot. These findings are consistent with those of $[8,13$, 14] who have found that the most common element of the accidents during the pilotage operations was due to inadequate master-pilot information sharing. Taken together, these results suggest that information sharing process should be continuously delivered in many stages during the operations and not only before the commencement of the pilotage operation. Other prevalent PSFs included Aspect of Communication and Information sharing, Training, Competency and Experience and Internal and External Environmental.

In conclusion of the findings in this step, TRACEr has attempted to include more systematic PSF contributing to accident occurrence and also classify the error of other personnel. The analysis of PSF was intended to avoid against the perception that human error study solely blame the operator for doing error without classify the other aspects that shaping their performance.

Table 8: Number of PSFS That Have Been Influence the Pilot Errors

\begin{tabular}{|c|c|}
\hline PSFs Group & Number \\
\hline 1. Aspect of Communication and Information sharing & 15 \\
\hline 2. Personal Issue/ Factor & 8 \\
\hline 3. Training, Competency and Experience & 12 \\
\hline 4. Internal and External Environmental & 10 \\
\hline $\begin{array}{l}\text { 5. Social and Crew Collaboration ( also including Bridge Team } \\
\text { Management ) }\end{array}$ & 7 \\
\hline 6. Organisation Factor & 2 \\
\hline 7. Machinery/propulsion and human machine interaction. & 7 \\
\hline 8. Procedure and documentation & 2 \\
\hline 9. Other factors & 12 \\
\hline
\end{tabular}




\subsubsection{Step 6: Analysis Completion.}

Finally, the error should be classified into four specific terms namely causal, contributory, compounding or non-contributory. Basically, this will be strongly based on the analyst judgment. Table 9 has summarized the result of classifying error group for 106 pilot errors from 50 accident reports. It suggested that the error caused by the pilot are significant since 62 out of 106 errors are considered as the ultimate cause of the accidents (causal).

Table 9: Types of Error Contribution Group

\begin{tabular}{|c|l|c|}
\hline $\begin{array}{c}\text { Contribution Group } \\
\text { Specification }\end{array}$ & \multicolumn{1}{|c|}{ Description } & $\begin{array}{c}\text { Number Of Pilot Errors } \\
\text { Based On 50 Accident Report }\end{array}$ \\
\hline Causal & $\begin{array}{l}\text { An ultimate cause of an incident, without } \\
\text { which the incident would not have occurred }\end{array}$ & $\mathbf{6 2}$ \\
\hline Contributory & $\begin{array}{l}\text { Error that contributes to the incident and } \\
\text { occurred in addition to the causal error but } \\
\text { the error would probably still have occurred } \\
\text { regardless. }\end{array}$ & $\mathbf{2 0}$ \\
\hline Compounding & $\begin{array}{l}\text { Errors that made the situation worse and } \\
\text { that occurred after the person realised that } \\
\text { the situation was going to occur. }\end{array}$ & $\mathbf{1 3}$ \\
\hline Non-contributory & $\begin{array}{c}\text { Other errors that occurred but had no } \\
\text { bearing on the incident. }\end{array}$ & $\mathbf{1 1}$ \\
\hline
\end{tabular}

\section{Conclusion}

The main limitation associated with this study was the set of taxonomy and classification contained in the TRACEr framework may always be incomplete and may always lead to uncertainties. These uncertainties can be overcome by increasing the number of accident reports and compare the analysis result with the probabilistic assessment approach. For that reason, this issue might appropriate to addressed by considering how TRACEr and probabilistic risk assessment (PRA) method could work together to provide a more comprehensive solution as well as more consistent with the current value and practice in the human error studies. Consequently, it would be interesting, if the results of TRACEr are use as part of the human error assessment data in the form of probability values.

In conclusion, this paper has demonstrated to use TRACEr (retrospective) methodology in facilitating the process of human errors identification in maritime pilotage operations. This method has a significant contribution to increase the consistency of findings as well as to prevent the possible manipulation of data in maritime accident investigation reports. Furthermore, this method will serve as a base for future HRA studies especially on the human cognitive errors aspects. Identifying the human cognitive errors that frequently result in the occurrence of maritime accidents can lead to the development of appropriate prevention and recovery options in Human Reliability Assessment (HRA) process. 


\section{References}

[1] Shorrock, S.T., Kirwan, B., (2002). Development and application of a human error identification tool for air traffic control. Applied Ergonomics, Vol.33 (4), 319-328.

[2] Kirwan .B. (2006). Sand: Safety Assessment for New Air Traffic Concept Exploration. EUROCONTROL Experimental Centre

[3] Melissa T.Baysari, Andrew Stuart Mcintosh,Carlo Caponececchia And John R.Wilson (2009) Classification of errors contributing to rail incidents and accidents: A comparison of two human error identification techniques. Safety Science, 47(7): p. 948-957.

[4] RSSB (2003). Tabular task analysis of the UK train driving task. Retrieved 07.09. 2011, from. www.rssb.co.uk

[5] Baysari, M. T., Carlo C., and Andrew S.M. (2011). A Reliability and Usability Study of TracerRav: The Technique for the Retrospective Analysis of Cognitive Errors - for Rail, Australian Version. Applied Ergonomics, Vol. 42(6), 852-859.

[6] Baysari, M.T., Mcintosh, A.S. and Wilson, J. (2008). Understanding the human factors contribution to railway accidents and incidents in Australia. Accident Analysis and Prevention Vol.40, 1750-1757.

[7] Ibrahim Adham Taib,Andrew Stuart Mcintosh,Carlo Caponececchia And Melissa T.Baysari (2011). A review of medical error taxonomies: A human factors perspective. Safety Science 49(5): 607-615.

[8] Graziano,A., Teixeira, A.P., Guedes Soares, C., 2016. Classification of Human Errors in Grounding and Collision Accidents Using the TRACEr Taxonomy. Safety Science 86, 245-257

[9] Schröder-Hinrichs, J.-U., Graziano, A., Praetorius, G. \& Kataria, A. (2017). TRCEr-Mar - Technique for the Retrospective \&

Predictive Analysis of Cognitive Errors adapted to the Maritime Domain (WMU Papers in Maritime and Ocean Affairs No.1). World Maritime University, Malmö, Sweden.

[10] Wickens, C.D (1992). Engineering Psychology and Human Performance, 2nd ed. Harper Collins Publishers Inc., New York. p.211.

[11] Rasmussen, J., Duncan, K.D., J. (1987). New Technology and Human Error. John Wiley \& Sons, Chichester, pp. 23-30.

[12] Neville Anthony Stanton, Alan Hedge, Karel Brookhuis, Eduardo Salas, Hal W. Hendrick (2005). Handbook of Human Factors And Ergonomic, CRC Press.

[13] National Occupational Standard (NOS) of UK (2010). A manual for Maritime Pilot

[14] Darbra, R.M. and Casal, J. (2004). Historical analysis of accidents in seaports. Safety Science Vol.42, pp.85-98 